\title{
A randomized comparison between costoclavicular and paracoracoid ultrasound-guided infraclavicular block for upper limb surgery
}

\section{Comparaison randomisée entre les blocs sous-claviculaires échoguidés costoclaviculaires et paracoracoïdes pour la chirurgie du membre supérieur}

\author{
Prangmalee Leurcharusmee, MD • Maria Francisca Elgueta, MD • \\ Worakamol Tiyaprasertkul, MD - Thitipan Sotthisopha, MD • Artid Samerchua, MD • \\ Aida Gordon, MD, FRCPC · Julian Aliste, MD • Roderick J. Finlayson, MD, FRCPC • \\ De Q. H. Tran, MD, FRCPC
}

Received: 28 November 2016/Revised: 21 December 2016/Accepted: 7 February 2017/Published online: 15 February 2017 (C) Canadian Anesthesiologists' Society 2017

\begin{abstract}
Background This two-centre randomized trial compared costoclavicular and paracoracoid ultrasound-guided infraclavicular brachial plexus block in patients undergoing upper limb surgery. We hypothesized that both techniques would result in similar onset times and designed the study as an equivalence trial.

Methods Ninety patients undergoing upper limb surgery at or distal to the elbow were randomly allocated to receive a costoclavicular $(n=45)$ or paracoracoid $(n=45)$ ultrasound-guided infraclavicular brachial plexus block. Both groups received a 35- $m L$ mixture of $1 \%$ lidocaine$0.25 \%$ bupivacaine with epinephrine $5 \mu \mathrm{g} \cdot \mathrm{mL} \mathrm{L}^{-1}$. In the costoclavicular group, local anesthetic was injected into the costoclavicular space in the middle of the three cords of the brachial plexus. In the paracoracoid group, local anesthetic was deposited dorsal to the axillary artery in the lateral infraclavicular fossa. A blinded observer recorded the block onset time (primary endpoint), success rate (i.e., surgical anesthesia), block-related pain scores, as well as the incidence of hemidiaphragmatic paralysis.
\end{abstract}

P. Leurcharusmee, MD · W. Tiyaprasertkul, MD

Department of Anesthesia, Maharaj Nakorn Chiang Mai

Hospital, Chiang Mai University, Chiang Mai, Thailand

M. F. Elgueta, MD - T. Sotthisopha, MD - A. Samerchua, MD .

A. Gordon, MD, FRCPC · J. Aliste, MD

R. J. Finlayson, MD, FRCPC - D. Q. H. Tran, MD, FRCPC ( $ه)$

Department of Anesthesia, Montreal General Hospital, McGill

University, Montreal, QC, Canada

e-mail: de_tran@hotmail.com
Performance time and the number of needle passes were also recorded during the performance of the block. The total anesthesia-related time was defined as the sum of the performance and onset times.

Results The mean (SD) onset times were comparable between the costoclavicular and paracoracoid groups [16.0 (7.5) min vs 16.8 (6.2) min, respectively; mean difference, $0.8 ; 95 \%$ confidence interval, -2.3 to $3.8 ; P=0.61]$. Furthermore, no intergroup differences were found in terms of performance time $(P=0.09)$, total anesthesia-related time $(P=0.90)$, surgical anesthesia $(P>0.99)$, and hemidiaphragmatic paralysis $(P>0.99)$. The paracoracoid technique required marginally fewer median [interquartile range] needle passes than the costoclavicular technique (2 [1-4] vs 2 [1-6], respectively; $P=0.048$ ); however, procedural pain was comparable between the two study groups.

Conclusion Costoclavicular and paracoracoid ultrasound-guided infraclavicular blocks resulted in similar onset times. Furthermore, no intergroup differences were found in terms of performance times and success rates. Future dose-finding trials are required to elucidate the minimum effective volume of local anesthetic for costoclavicular infraclavicular blocks. This trial was registered at www.clinicaltrials.in.th (Study ID: TCTR20160525001).

Résumé

Contexte Cette étude randomisée menée dans deux centres a comparé les blocs sous-claviculaires échoguidés $d u$ plexus brachial costoclaviculaires et 
paracoracoüdes chez des patients devant subir une chirurgie du membre supérieur. Nous avons formulé l'hypothèse que les deux techniques obtiendraient des résultats dans les mêmes délais et avons conçu cette recherche comme une étude d'équivalence.

Méthodes Quatre-vingt-dix patients subissant une chirurgie du membre supérieur au niveau du coude ou en plus distal ont été répartis pour recevoir un bloc sousclaviculaire échoguidé du plexus brachial par voie costoclaviculaire $(n=45)$ ou paracoracoïde $(n=45)$. Les deux groupes ont reçu un mélange de $35 \mathrm{~mL}$ de lidocaïne à $1 \%$ - bupivacä̈ne à 0,25\% et d'épinéphrine à raison de $5 \mu \mathrm{g} \cdot \mathrm{mL}^{-1}$. Dans le groupe costoclaviculaire, l'anesthésique local a été injecté dans l'espace costoclaviculaire au milieu des 3 branches du plexus brachial. Dans le groupe paracoracoïde, l'anesthésique local a été déposé en arrière de l'artère axillaire dans la fosse sous-claviculaire externe. Un observateur tenu dans l'insu de la technique a enregistré le temps d'installation du bloc (critère d'évaluation principal), le taux de succès (c'est-à-dire, l'anesthésie chirurgicale), les scores de douleur liés au bloc ainsi que l'incidence de la paralysie hémidiaphragmatique. Le temps de réalisation et le nombre de passages de l'aiguille ont également été consignés pendant la réalisation du bloc. Le temps total lié à l'anesthésie a été défini comme la somme du temps de réalisation et du délai d'installation du bloc.

Résultats Les délais d'installation moyens (É-T) des groupes costoclaviculaires et paracoracö̈des ont été comparables (respectivement 16,0 [7,5] minutes contre 16,8 [6,2] minutes; différence des moyennes, 0,8; intervalle de confiance à $95 \%:-2,3$ à 3,8; $P=0,61$ ). En outre, aucune différence n'a été constatée entre les groupes pour ce qui concerne le temps de réalisation $(P=0,09)$, le temps total lié à l'anesthésie $(P=0,90)$, l'anesthésie chirurgicale $(P>0.99)$ et la paralysie hémidiaphragmatique $(P>0.99)$ La technique paracoracoüde a nécessité un nombre médian marginalement moindre (écart interquartile) de passages d'aiguille que la technique costoclaviculaire (respectivement 2 [1 à 4] contre 2 [1 à 6]); $P=0,048$ ). Néanmoins, la douleur liée à la procédure a été comparable dans les deux groupes de l'étude.

Conclusion Les blocs sous-claviculaires échoguidés costoclaviculaires et paracoracoüdes ont abouti à des temps d'installation similaires. De plus, aucune différence n'a été trouvée entre les groupes concernant les temps de réalisation et les taux de succès. Des essais futurs de détermination de dose sont nécessaires pour préciser le volume efficace minimum d'anesthésique local pour les blocs sous-claviculaires costoclaviculaires. Cette étude a été enregistrée sur le site www.clinicaltrials.in.th (ID de l'étude : TCTR20160525001).
Ultrasound (US)-guided infraclavicular block (ICB) anesthetizes the brachial plexus at the level of its cords and provides reliable anesthesia and analgesia for upper extremity surgery. ${ }^{1}$ The conventional (paracoracoid) ICB technique aims to deposit local anesthetic (LA) dorsal to the axillary artery in the lateral infraclavicular fossa., Karmakar et $a l^{4}$ have recently described a new costoclavicular ICB method whereby the brachial plexus is targeted immediately caudal to the clavicle in the costoclavicular space. In the latter method, the three cords of the brachial plexus are tightly clustered together. Consequently, Karmakar et al. speculated that the more compact costoclavicular topography would result in a "very rapid onset of brachial plexus blockade similar to that seen with a supraclavicular approach".

Despite the potential anatomical benefits associated with a costoclavicular technique, our general experience reveals a similar block onset time between the latter and its paracoracoid counterpart (unpublished data). Thus, in this two-centre randomized-controlled trial, we set out to conduct a formal comparison between US-guided costoclavicular and paracoracoid ICBs. Our primary endpoint was onset time (defined as the time required to reach a minimal score of 14/16 points using a sensorimotor composite scale). The secondary outcomes included block performance time and success rate (i.e., surgical anesthesia), number of needle passes, overall procedural pain, and the incidence of adverse events (e.g., vascular breach, paresthesia, hemidiaphragmatic paralysis). In keeping with our clinical experience, we hypothesized that costoclavicular and paracoracoid ICBs would provide a similar onset time; thus, we designed the study as an equivalence trial.

\section{Methods}

After securing Ethics Committee approval (August, 2016 for the McGill University Health Centre, Montreal, Canada and August, 2016 for the Maharaj Nakorn Chiang Mai Hospital, Chiang Mai, Thailand) and obtaining written informed consent, we enrolled 90 patients undergoing surgery of the elbow, forearm, wrist, or hand. Inclusion criteria were: age between 1880 yrs of age, American Society of Anesthesiologists physical status I- III, and body mass index $18-35 \mathrm{~kg} \cdot \mathrm{m}^{-2}$. Exclusion criteria included the inability to consent to the study, coagulopathy, sepsis, hepatic or renal failure, allergy to LA, preexisting musculocutaneous/median/ radial/ ulnar neuropathy, and prior surgery in the infraclavicular fossa.

After arrival in the induction room, intravenous premedication (midazolam $0.03 \mathrm{mg} \cdot \mathrm{kg}^{-1}$ and fentanyl 0.6 
$\mu \mathrm{g} \cdot \mathrm{kg}^{-1}$ ) was administered to all patients. Supplemental oxygen (nasal cannulae at $4 \mathrm{~L} \cdot \mathrm{min}^{-1}$ ) and pulse oximetry were applied throughout the procedure. Operators (residents, fellows, or staff anesthesiologists) were considered experts for a given technique if, prior to the start of the study, they possessed an experience level of at least 60 US-guided ICBs. Otherwise, they were considered trainees. ${ }^{7}$ Three investigators supervised all the blocks (P.L., M.F.E., D.Q.H.T.). Using a computer-generated sequence of random numbers and a sealed envelope technique, patients were randomly allocated to receive costoclavicular $(n=45)$ or paracoracoid $(n=45)$ USguided ICB. Subjects were randomized in blocks of ten to ensure equal distribution between the two study groups. The Chiang Mai and Montreal centres were assigned five and four blocks of ten patients, respectively. A 6-13 MHz linear US transducer (SonoSite M-Turbo ${ }^{\circledR}$, SonoSite ${ }^{\circledR}$ Inc, Bothell, WA, USA), 22G 9-cm block needle (StimuQuik ${ }^{\circledR}$ ECHO, Arrow ${ }^{\circledR}$ International Inc, Reading, PA, USA), and a lidocaine/bupivacaine mixture (1\% lidocaine- $0.25 \%$ bupivacaine with epinephrine $5 \mu \mathrm{g} \cdot \mathrm{mL}^{-1}$, obtained by mixing equal parts of $2 \%$ lidocaine and $0.5 \%$ bupivacaine before adding epinephrine $5 \mu \mathrm{g} \cdot \mathrm{mL}^{-1}$ ) were used for all subjects.

The paracoracoid ICB was performed according to a previously described technique. ${ }^{1,2}$ The US probe was applied in a sterile fashion in the lateral infraclavicular fossa medially to the coracoid process in order to obtain a short-axis view of the axillary artery (Fig. 1A). After skin infiltration, using an in-plane technique and a cephalad-tocaudad direction, the block needle was advanced until its tip was located dorsal to the axillary artery. Thirty-five $\mathrm{mL}$ of the LA mix were incrementally injected.

In the costoclavicular ICB group, patients were placed in a supine position with the surgical limb in $90^{\circ}$ abduction. ${ }^{6}$ The US probe was initially placed directly on top of the middle third of the clavicle. Subsequently, the probe was translocated off the inferior border of the clavicle and positioned in the medial infraclavicular fossa. In the costoclavicular space, the axillary artery was identified underneath the subclavius muscle. The three cords of the brachial plexus were visualized lateral to the artery (Fig. 1B). If the cephalic vein (or thoracoacromial artery) was visualized, the US transducer was tilted slightly cephalad in order to provide an adequate sonographic view of the costoclavicular space and the three cords of the brachial plexus. After skin infiltration, using an in-plane technique and a lateral-to-medial direction, the block needle was advanced until its tip was located in the middle of all three cords. ${ }^{4,6}$ Thirty-five $\mathrm{mL}$ of the LA mix were incrementally injected.

For both groups, the imaging time was defined as the temporal interval between contact of the US probe with the
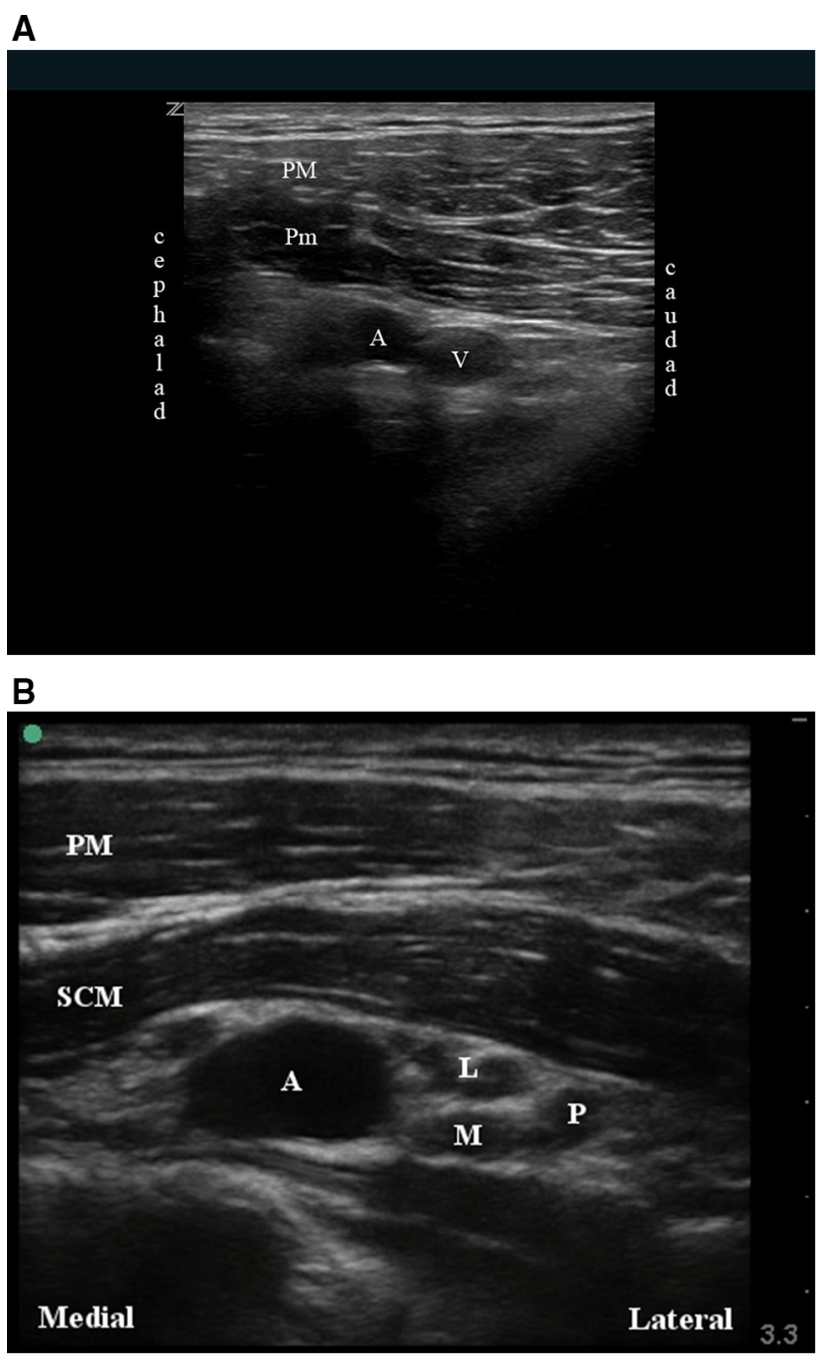

Fig. 1 A. Sonographic view of the brachial plexus in the lateral infraclavicular fossa; B. Sonographic view of the brachial plexus in the costoclavicular space. $\mathrm{L}=$ lateral cord; $\mathrm{M}=$ medial cord; $\mathrm{P}=$ posterior cord; $\mathrm{PM}=$ pectoralis major muscle; $\mathrm{Pm}=$ pectoralis minor muscle; $\mathrm{SCM}=$ subclavius muscle; $\mathrm{V}=$ axillary vein

patient and the acquisition of a satisfactory image. The needling time (defined as the temporal interval between skin infiltration and the end of LA injection through the block needle) was also recorded. Thus, performance time equalled the sum of imaging and needling times. The number of needle passes was also recorded. The initial needle insertion counted as the first pass. Any subsequent needle advancement that was preceded by a retraction of at least $10 \mathrm{~mm}$ counted as an additional pass. ${ }^{8}$ The investigator supervising the ICB recorded the imaging/ needling times, number of passes, and occurrence of adverse events (e.g., vascular puncture).

After LA injection through the block needle, measurements of brachial plexus blockade were carried out by a blinded observer every $5 \mathrm{~min}$ until $30 \mathrm{~min}$. 
Sensory blockade of the musculocutaneous, median, radial, and ulnar nerves was graded according to a three-point scale using a cold test: $0=$ no block; $1=$ analgesia (patient can feel touch, not cold); 2 = anesthesia (patient cannot feel touch). ${ }^{1,2,9}$ Sensory blockade of the musculocutaneous, median, radial, and ulnar nerves was assessed on the lateral aspect of the forearm, the volar aspect of the thumb, the lateral aspect of the dorsum of the hand, and the volar aspect of the fifth finger, respectively. ${ }^{1,2,9}$ Motor blockade was also graded on a three-point scale: $0=$ no block; $1=$ paresis; 2 = paralysis. $^{1,2,9}$ Motor blockade of the musculocutaneous, radial, median, and ulnar nerves was evaluated by elbow flexion, thumb abduction, thumb opposition, and thumb adduction, respectively. ${ }^{1,2,9}$ Overall, the maximal composite sensorimotor score was 16 points. We considered the block a success and the patient ready for surgery when a minimal composite score of 14 points was achieved, provided the sensory block score was equal or superior to 7 out of 8 points. This scale has been used in previous studies. ${ }^{1,2,9}$ Thus, the block onset time (i.e., the primary endpoint) was defined as the time required to obtain $\geq 14$ points after the end of LA injection through the block needle. Total anesthesia-related time was defined as the sum of performance and onset times. If the composite score was inferior to 14 points after $30 \mathrm{~min}$, the patient was transferred to the operating room for the start of the surgery. For these subjects, we did not record an onset time and did not perform supplemental blocks. The same blinded observer recorded surgical anesthesia, defined as the capacity to undergo surgery without the need for intravenous narcotics, general anesthesia, rescue blocks, or LA infiltration by the surgeon. ${ }^{1,2,9}$ Nevertheless, subjects could receive a propofol infusion $\left(25-80 \mu \mathrm{g} \cdot \mathrm{kg}^{-1} \cdot \mathrm{min}^{-1}\right)$ intraoperatively provided response to verbal stimulus was maintained. The blinded observer also recorded the patient's anthropometric data as well as the incidence of paresthesia, Horner syndrome, hoarseness, and the level of block-related pain $(0=$ no pain; $10=$ worst imaginable pain). Furthermore, $30 \mathrm{~min}$ after the ICB, the blinded investigator assessed diaphragmatic motion with $\mathrm{M}$-mode US. Hemidiaphragmatic paralysis was defined as absent diaphragm movement with inspiration coupled with absent or paradoxical (i.e., downward deflection) movement when the patient sniffs. ${ }^{10}$

One week after the surgery, the blinded investigator contacted patients by telephone to inquire about complications such as persistent numbness or paresthesia and motor deficits.

\section{Statistical analysis}

Our experience with paracoracoid US-guided ICB revealed a mean (SD) onset time of 17.1 (6.3) min. ${ }^{11}$ We deemed that a $30 \%$ relative difference in onset time (i.e., $5.1 \mathrm{~min}$ ) carries minimal clinical significance and therefore set our equivalence margin at $\pm 5.1 \mathrm{~min}$. Thus, a calculated sample size of 40 patients per group was required to provide a statistical power of 0.90 and a type I error of 0.025 . Since onset time can only be calculated for successful blocks, 90 subjects were recruited to account for an anticipated $10 \%$ failure rate. ${ }^{9}$

We elected to design the current protocol as an equivalence instead of a superiority trial because our preliminary experience with costoclavicular ICB led us to suspect that its onset time would be similar to the one provided by paracoracoid ICB. From a conceptual standpoint, we also eschewed the non-inferiority design since we aimed to show that costoclavicular ICB is no better or no worse than its paracoracoid counterpart. In contrast, a non-inferiority trial would have been indicated had we wanted to demonstrate only that the new treatment (i.e., costoclavicular ICB) is no worse than the active control (i.e., paracoracoid ICB). ${ }^{12}$

Statistical analysis was performed using SPSS ${ }^{\circledR}$ version 21 statistical software (IBM Armonk, NY, USA). For continuous data, normality was first assessed with Lilliefors test, and if normal distribution was not rejected, we employed the Student's $t$ test. Data that did not have a normal distribution, as well as ordinal data, was analyzed with the Mann-Whitney $U$ test. For categorical data, Pearson's Chi square test was used. When the expected count was less than five, Fisher's exact test was employed. All $P$ values presented are two-sided and values $<0.05$ were considered significant.

\section{Results}

The 90 subjects were recruited from mid-August 2016 to mid-October 2016 (Fig. 2). As planned, 50 and 40 patients were enrolled in Chiang Mai and Montreal, respectively. The costoclavicular and paracoracoid groups were comparable in terms of anthropometric data and surgical procedures (Table 1).

Our primary endpoint, mean (SD) onset time, was similar between the costoclavicular and paracoracoid groups [16.0 (7.5) $\mathrm{min} v s 16.8$ (6.2) $\mathrm{min}$, respectively; mean difference, $0.8 ; 95 \% \mathrm{CI},-2.3$ to $3.8 ; P=0.61$ ] (Table 2). Furthermore, no intergroup differences were found in terms of performance time $(P=0.09)$, total anesthesia-related time $(P=0.90)$, surgical anesthesia $(P>0.99)$, and hemidiaphragmatic paralysis $(P>0.99)$. The proportions of blocks achieving minimal composite scores of 14 points at the different five-minute intervals were also similar between the two groups (Fig. 3). The paracoracoid technique required marginally fewer median 
Fig. 2 CONSORT diagram of patient flow through the study. The primary outcome (onset time) and total anesthesiarelated time could not be recorded for patients with minimal composite scores $<14$ points at $30 \mathrm{~min}$. However, imaging/ needling/ performance times, number of needle passes, procedural pain, operator's experience level, adverse events (e.g., vascular breach, paresthesia, hemidiaphragmatic paralysis) and surgical anesthesia were recorded for these subjects

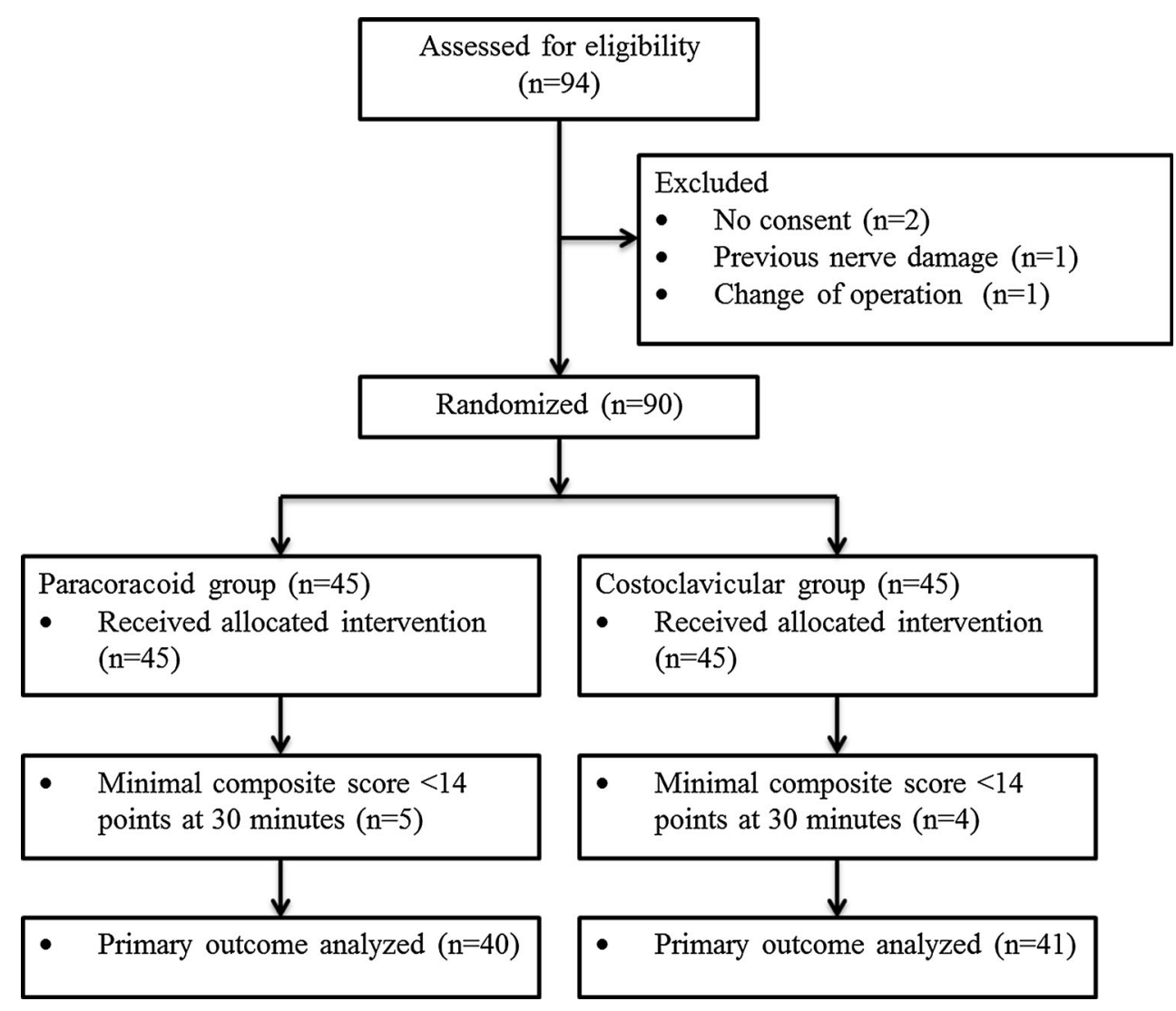

Table 1 Patient characteristics

\begin{tabular}{lll}
\hline & $\begin{array}{l}\text { Paracoracoid } \\
\text { group } \\
(n=45)\end{array}$ & $\begin{array}{l}\text { Costoclavicular } \\
\text { group } \\
(n=45)\end{array}$ \\
\hline Age $(\mathrm{yr})$ & $40.9(16.2)$ & $42.8(16.4)$ \\
Sex $(\mathrm{M} / \mathrm{F})$ & $19 / 26$ & $28 / 17$ \\
$\mathrm{BMI}\left(\mathrm{kg} \cdot \mathrm{m}^{-2}\right)$ & $24.1(3.9)$ & $23.4(3.5)$ \\
$\begin{array}{l}\text { ASA physical status (I/ II/ III) } \\
\begin{array}{l}\text { Types of surgery (hand/ wrist/ } \\
\text { forearm/ elbow) }\end{array}\end{array}$ & $29 / 15 / 1$ & $28 / 14 / 3$ \\
\hline
\end{tabular}

Continuous variables are presented as means (standard deviation); categorical variables are presented as counts. ASA $=$ American Society of Anesthesiologists; BMI = body mass index

[interquartile range] needle passes compared with the costoclavicular technique (2 [1-4] vs 2 [1-6], respectively; $P=0.048$ ); however, procedural pain was comparable between the two study groups (Table 2).

In the first five minutes after the ICB, more patients in the costoclavicular group displayed complete sensory and motor block in the territories of the musculocutaneous/ radial/ulnar nerves and musculocutaneous/median/ulnar nerves, respectively. After ten minutes, however, sensory and motor blockade of the musculocutaneous, median, and ulnar nerves were comparable between the two groups. Sensory blockade of the radial nerve was more prevalent in the costoclavicular group until $20 \mathrm{~min}$. No intergroup differences were found thereafter (Figs 4 and 5).

Patient follow-up one week after the surgery revealed no persistent sensory or motor deficits.

\section{Discussion}

In this randomized observer-blinded trial, we compared costoclavicular and paracoracoid US-guided ICBs. No intergroup differences were observed in terms of block onset times (primary endpoint) or overall success rates (i.e., surgical anesthesia). We speculate that these findings might be partially explained by the LA volume used. Although the brachial plexus displays a more compact topography in the costoclavicular space (where the costoclavicular ICB is performed) than in the lateral infraclavicular fossa (where the paracoracoid ICB is performed), these anatomical differences were most likely compensated by the large injectate $(35 \mathrm{~mL})$. This may explain why the costoclavicular technique initially provided better sensorimotor blockade, but after ten minutes, LA spread 
Table 2 Block performance data

\begin{tabular}{|c|c|c|c|c|c|}
\hline & $\begin{array}{l}\text { Paracoracoid } \\
\text { group } \\
(n=45)\end{array}$ & $\begin{array}{l}\text { Costoclavicular } \\
\text { group } \\
(n=45)\end{array}$ & $\begin{array}{l}\text { Difference of the } \\
\text { means }\end{array}$ & $95 \% \mathrm{CI}$ & $P$ value \\
\hline Imaging time (sec) & $24.8(18.4)$ & $43.7(29.1)$ & -18.9 & -29.1 to -8.7 & $<0.001 *$ \\
\hline Needling time (min) & $5.6(2.1)$ & $6.0(1.7)$ & -0.4 & -1.2 to 0.4 & $0.29 \dagger$ \\
\hline Performance time (min) & $6.0(2.1)$ & $6.7(2.0)$ & -0.7 & -1.6 to 0.1 & $0.09 \dagger$ \\
\hline Onset time $(\min )$ & $16.8(6.2)$ & $16.0(7.5)$ & 0.8 & -2.3 to 3.8 & $0.61 \dagger$ \\
\hline Total anesthesia-related time (min) & $22.6(6.2)$ & $22.8(7.4)$ & -0.2 & -1.6 to 0.1 & $0.90 \dagger$ \\
\hline $\begin{array}{l}\text { Blocks with a minimal composite score of } 14 \\
\text { points }\end{array}$ & $40(88.9)$ & $41(91.1)$ & NA & NA & $0.76 \uparrow$ \\
\hline Surgical anesthesia & $44(97.8)$ & $43(95.6)$ & NA & NA & $>0.99 \bullet$ \\
\hline Operator's experience level (expert/trainee) & $7 / 38$ & $11 / 34$ & NA & NA & $0.43 \uparrow$ \\
\hline Number of passes & $2[1-4]$ & $2[1-6]$ & NA & NA & $0.048^{*}$ \\
\hline Block-related pain (scale 0-10) & $0[0-7]$ & $0[0-8]$ & NA & NA & $0.85^{*}$ \\
\hline Vascular puncture & $4(8.9)$ & $1(2.2)$ & NA & NA & $0.36 \S$ \\
\hline Paresthesia & $0(0)$ & $2(4.4)$ & NA & NA & $0.49^{\S}$ \\
\hline Hemidiaphragmatic paralysis & $4(8.9)$ & $4(8.9)$ & NA & NA & $>0.99 \S$ \\
\hline Horner syndrome & $2(4.4)$ & $0(0)$ & NA & NA & $0.49 \S$ \\
\hline Hoarseness & $0(0)$ & $0(0)$ & NA & NA & $>0.99 \S$ \\
\hline
\end{tabular}

Continuous variables are presented as mean (standard deviation); categorical variables are presented as count (percentage). Ordinal variables (number of passes, block-related pain) are presented as median [range]. Onset and total anesthesia-related times are calculated only for patients with a minimal composite score of 14 points at $30 \mathrm{~min}$. $\mathrm{CI}=$ confidence interval; $\mathrm{NA}=$ not applicable

* Wilcoxon-Mann-Whitney test; †Student's $t$ test; $\uparrow$ Chi square test; § Fisher’s exact test

in the paracoracoid group started to minimize differences between the two methods. In the current study, due to the absence of dose-finding trials for the $1.0 \%$ lidocaine$0.25 \%$ bupivacaine mixture, we selected a $35-\mathrm{mL}$ injectate because this volume corresponds to the documented minimum effective volume of $1.5 \%$ lidocaine in $90 \%$ of patients $\left(\mathrm{MEV}_{90}\right)$ for paracoracoid ICB. ${ }^{9}$ In their original description, Karmakar et al. ${ }^{4}$ used only $20 \mathrm{~mL}$ for costoclavicular ICB. Thus, we cannot rule out the possibility that the costoclavicular technique may outperform its paracoracoid counterpart with smaller LA volumes. Therefore, future dose-finding trials should attempt to elucidate the $\mathrm{MEV}_{90}$ for costoclavicular ICB.

Our costoclavicular ICB technique deserves special mention. Karmakar et al. ${ }^{4,6}$ advocated dual guidance with US and neurostimulation "until the operator is familiar with the sonoanatomy of the [costoclavicular space]". Although most of our operators were novices, we decided to forego neurostimulation altogether and relied solely on US guidance. In two previous randomized trials (combined $n=182$ ), Dingemans et al. ${ }^{13}$ and Gurkan et al. ${ }^{14}$ have shown that, compared with US alone, combined USneurostimulation unnecessarily increased the performance time $^{13,14}$ and resulted in a lower success rate ${ }^{13}$ for paracoracoid ICB. Thus, we similarly reasoned that nerve stimulation would confer no benefits for US-guided costoclavicular ICB. Furthermore, we believe that the sole use of US did not impact our primary outcome (onset time), as review of Karmakar et al.'s description clearly reveals that the optimal target corresponded to needle tip placement in the middle of the three cords of the brachial plexus. $^{4-6}$ In these studies, neurostimulation was not used to shorten onset time. Instead, it served only as a failsafe mechanism for the lateral-to-medial needle path-in other words, the occurrence of evoked motor response acted as a backstop and ensured that inexperienced operators would not introduce the needle tip past the cords into the pleura., ${ }^{4,6}$

The incidences of ipsilateral phrenic nerve block, vascular puncture, and paresthesia require discussion. In both groups, $9 \%$ of subjects displayed complete hemidiaphragmatic paralysis. In a recent trial, Petrar et al. ${ }^{15}$ reported a mere $3 \%$ rate of diaphragmatic paresis at $30 \mathrm{~min}$ after paracoracoid ICB. We hypothesize that the discrepancy can be explained by a difference in LA volume (and spread), as we used $35 \mathrm{~mL}$ whereas Petrar et al. ${ }^{15}$ employed $30 \mathrm{~mL}$. Our findings also reveal a higher incidence of vascular breach $(8.9 \%$ vs $2.2 \%)$ with paracoracoid ICB and a higher risk of paresthesia $(4.4 \%$ vs $0 \%$ ) with costoclavicular ICB. Intergroup differences did not reach statistical significance because our trial was 
Fig. 3 Percentage of patients with a minimal composite score of 14 points according to time. Absolute counts are provided inside each column. NS = not statistically significant
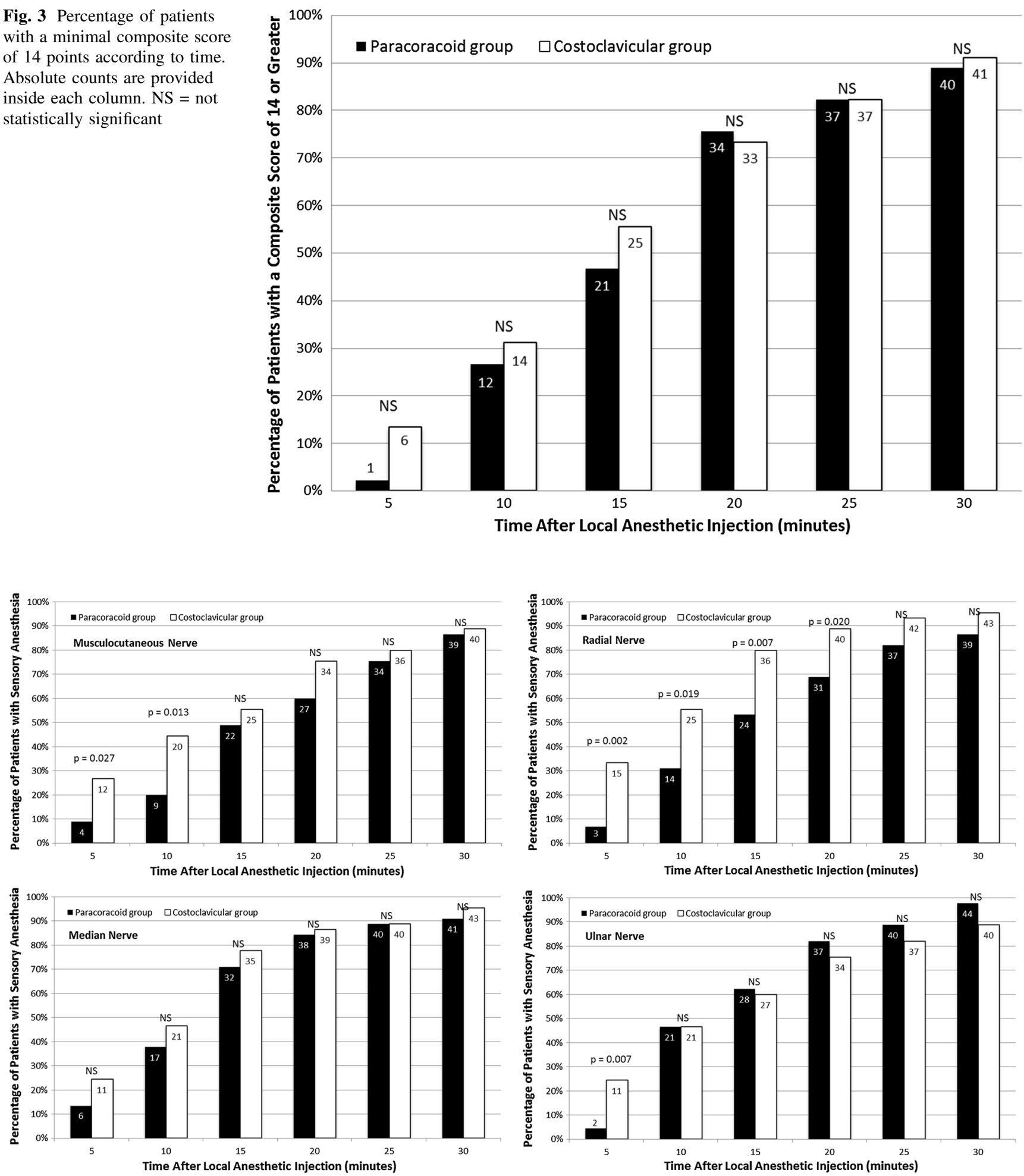

Fig. 4 Percentage of patients with sensory anesthesia (score of 2) according to time in the cutaneous distributions of the radial, median, ulnar, and musculocutaneous nerves. Absolute counts are provided inside each column. NS = not statistically significant

insufficiently powered to investigate the incidence of these adverse events. Nonetheless, we attribute their occurrence to the physical target (and needle path) required by each technique-i.e., the paracoracoid method necessitated placement of the needle tip contiguous to the axillary artery (6 o'clock position), while its costoclavicular 

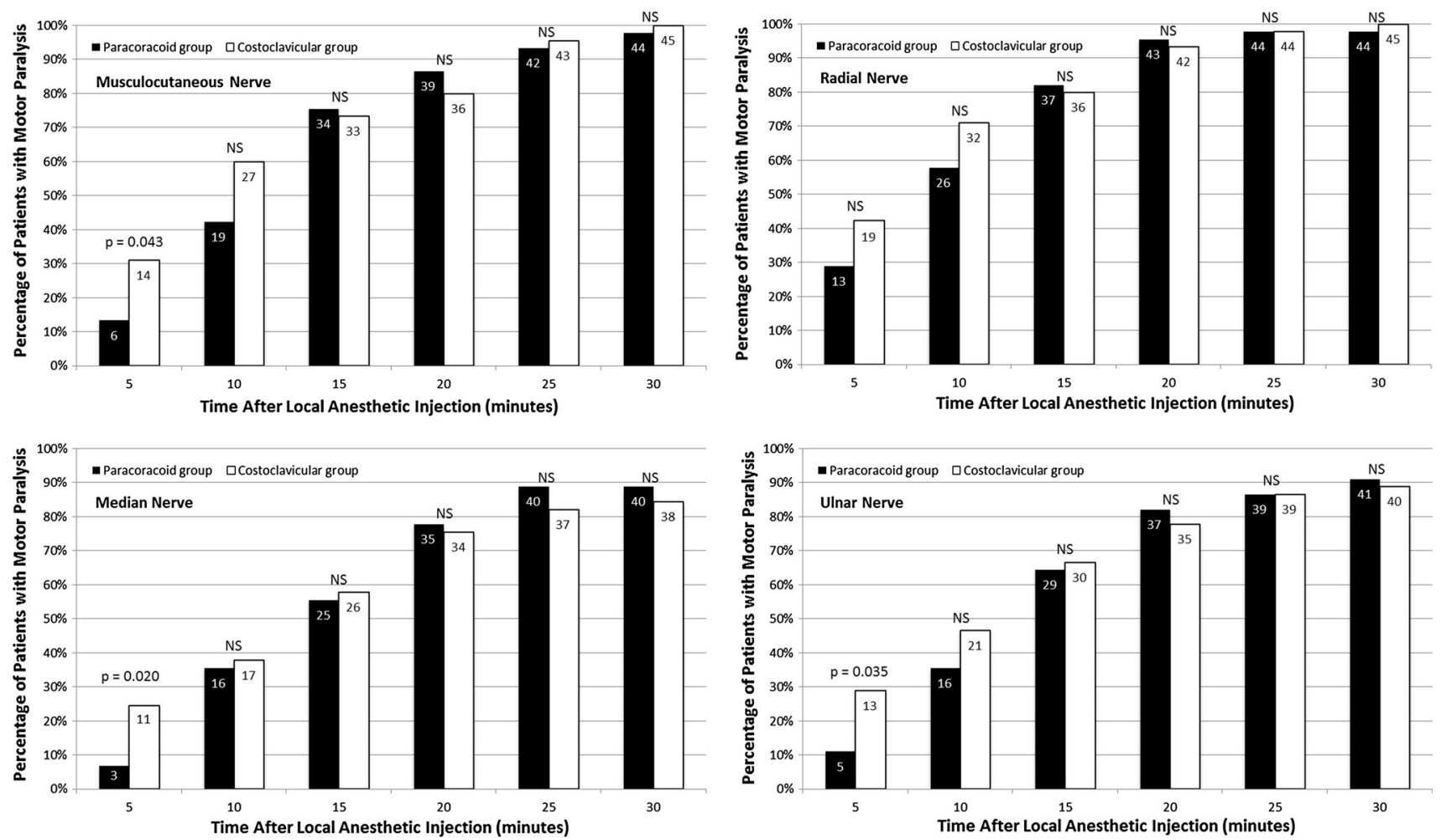

Fig. 5 Percentage of patients with motor paralysis (score of 2) according to time in the distributions of the radial, median, ulnar, and musculocutaneous nerves. Absolute counts are provided inside each column. NS $=$ not statistically significant

counterpart aimed to position the needle tip in the middle of the three cords of the brachial plexus.

The results of our current trial carry clinical implications that will require investigation by future studies. Despite its track record for efficacy and safety, ${ }^{1,2,9,11}$ paracoracoid US-guided ICB can be technically challenging in patients with elevated body mass indices. In such cases, conventional strategies include shoulder abduction, which is purported to decrease the depth of the three cords, ${ }^{16}$ or the selection of an alternative method to anesthetize the brachial plexus (i.e., supraclavicular or axillary block). ${ }^{1}$ Because the three cords are relatively superficial in the costoclavicular space, ${ }^{17}$ the costoclavicular ICB may provide a valuable alternative to its paracoracoid counterpart in subsets of patients with decreased visibility of the axillary artery in the lateral infraclavicular fossa. Furthermore, we hypothesize that coagulopathic patients requiring ICB could also benefit from the costoclavicular technique, as the target point is not perivascular but located in the middle of the three cords of the brachial plexus.

Our protocol does present some limitations. First, in keeping with the Karmakar et al. original recommendation, ${ }^{4}$ we injected the entire LA volume into the middle of the three cords of the brachial plexus for costoclavicular ICB. Future trials could determine if a multiple-injection method or a cord-targeting technique might result in a shorter onset time. Second, our results are specific to the $1 \%$ lidocaine- $0.25 \%$ bupivacaine mixture. Due to its compact topography, the costoclavicular space may represent a better injection site than the lateral infraclavicular fossa for LA with long latency (e.g., bupivacaine or ropivacaine). Further trials are required to compare paracoracoid and costoclavicular ICB for LA with a slower onset.

In conclusion, costoclavicular and paracoracoid USguided ICBs resulted in similar onset times. Furthermore no intergroup differences were found in terms of performance times and success rates. Future dose-finding trials are required to elucidate the $\mathrm{MEV}_{90}$ for costoclavicular ICB.

Acknowledgements The authors thank Mr. Derek Mitchell as well as Drs Richard Bondy, Andrew Owen, and Gina Wu for their invaluable assistance with patient recruitment.

\section{Conflicts of interest None declared.}

Editorial responsibility This submission was handled by Dr. Hilary P. Grocott, Editor-in-Chief, Canadian Journal of Anesthesia.

Author contributions Prangmalee Leurcharusmee, Maria Francisca Elgueta, Roderick J. Finlayson, and De Q.H. Tran designed the trial and helped write the manuscript. Prangmalee Leurcharusmee, Maria Francisca Elgueta, Worakamol 
Tiyaprasertkul, Thitipan Sotthisopha, Artid Samerchua, Aida Gordon, Julian Aliste, Roderick J. Finlayson, and De Q.H. Tran helped conduct the study as well as collect and analyze the data.

Funding None of the authors received funding for this study.

\section{References}

1. Tran DQ, Russo G, Munoz, L, Zaouter C, Finlayson RJ. A prospective, randomized comparison between ultrasound-guided supraclavicular, infraclavicular, and axillary brachial plexus blocks. Reg Anesth Pain Med 2009; 34: 366-71.

2. Tran DQ, Bertini P, Zaouter $C$, Munoz L, Finlayson RJ. A prospective, randomized comparison between single- and doubleinjection ultrasound-guided infraclavicular brachial plexus block. Reg Anesth Pain Med 2010; 35: 16-21.

3. Desgagnes $M C$, Levesque $S$, Dion $N$, et al. A comparison of a single or triple injection technique for ultrasound-guided infraclavicular block: a prospective randomized controlled study. Anesth Analg 2009; 109: 668-72.

4. Karmakar MK, Sala-Blanch X, Songthamwat B, Tsui BC. Benefits of the costoclavicular for ultrasound-guided infraclavicular brachial plexus block: description of a costoclavicular approach. Reg Anesth Pain Med 2015; 40: 287-8.

5. Sala-Blanch $X$, Reina MA, Pangthipampai P, Karmakar MK. Anatomic basis for brachial plexus block at the costoclavicular space: a cadaver anatomic study. Reg Anesth Pain Med 2016; 41: 387-91.

6. Karmakar MK, Songthamwat B. Costoclavicular brachial plexus block. In: Karmakar MK, editor. Musculoskeletal Ultrasound for Regional Anesthesia and Pain Medicine. 2nd ed. Hong Kong, China: CU Medicine; 2016 .

7. Konrad C, Schupfer G, Wietlisbach M, Gerber H. Learning manual skills in anesthesiology: is there a recommended number of cases for anesthetic procedures? Anesth Analg 1998; 86: 6359.

8. Casati A, Danelli $G$, Baciarello $M$, et al. A prospective, randomized comparison between ultrasound and nerve stimulation guidance for multiple injection axillary brachial plexus block. Anesthesiology 2007; 106: 992-6.

9. Tran DQ, Dugani S, Diachenko A, Correa JA, Finlayson RJ. Minimum effective volume of lidocaine for ultrasound-guided infraclavicular block. Reg Anesth Pain Med 2011; 36: 190-4.

10. Loyd T, Tang YM, Benson MD, King S. Diaphragmatic paralysis: the use of M mode ultrasound for diagnosis in adults. Spinal Cord 2006; 44: 505-8.

11. Leurcharusmee P, Aliste J, Van Zundert TC, et al. A multicenter randomized comparison between intravenous and perineural dexamethasone for ultrasound-guided infraclavicular block. Reg Anesth Pain Med 2016; 41: 328-33.

12. Lesaffre E. Superiority, equivalence, and non-inferiority trials. Bull NYU Hosp Jt Dis 2008; 66: 150-4.

13. Dingemans E, Williams SR, Arcand G, et al. Neurostimulation in ultrasound-guided infraclavicular block: a prospective randomized trial. Anesth Analg 2007; 104: 1275-80.

14. Gurkan Y, Tekin M, Acar S, Solak M, Toker $K$. Is nerve stimulation needed during an ultrasound-guided lateral sagittal infraclavicular block? Acta Anaesthesiol Scand 2010; 54: 403-7.

15. Petrar SD, Seltenrich ME, Head SJ, Schwarz SK. Hemidiaphragmatic paralysis following ultrasound-guided supraclavicular versus infraclavicular brachial plexus blockade: a randomized clinical trial. Reg Anesth Pain Med 2015; 40: 1338.

16. Ruiz A, Sala X, Bargallo X, Hurtado P, Arguis MJ, Carrera A. The influence of arm abduction on the anatomic relations of infraclavicular brachial plexus: an ultrasound study. Anesth Analg 2009; 108: 364-6.

17. Yoshida T, Watanabe $Y$, Furutani $K$. Proximal approach for ultrasound-guided infraclavicular brachial plexus block. Acta Anaesthesiol Taiwan 2016; 54: 31-2. 